\title{
Polychlorinated naphthalenes and other chlorinated tricyclic aromatic hydrocarbons emitted from combustion of polyvinylchloride
}

\author{
Dongli Wang a ${ }^{\mathrm{a}}$, Xiaobai $\mathrm{Xu}^{\mathrm{a}}{ }^{\mathrm{*}}$, Shaogang Chu ${ }^{\mathrm{b}}$, Qing X. $\mathrm{Li}^{\mathrm{c}}$ \\ a Research Center for Eco-Environmental Sciences, Chinese Academy of Sciences, \\ 18 Shuangqing Road, Haidian District, Beijing 100085, China \\ ${ }^{\mathrm{b}}$ Great Lakes Institute for Environmental Research, University of Windsor, Windsor, Ontario, Canada N9B 3P4 \\ ${ }^{\mathrm{c}}$ Department of Molecular Biosciences and Bioengineering, University of Hawaii, Honolulu, HI 96822, USA \\ Received 14 March 2005; received in revised form 15 October 2005; accepted 21 March 2006 \\ Available online 20 May 2006
}

\begin{abstract}
Chloronaphthalenes (CNs) and phenanthrenes or/and anthracenes (CP/CAs) were detected in the emissions of polyvinylchloride (PVC) combustion at $900{ }^{\circ} \mathrm{C}$. The presence of metallic iron, copper, or aluminum increased the formation of highly chlorinated CNs (tri- to octachloro-homologues) in the PVC combustion process. Total levels of CNs and CP/CAs were 40-48 and 76-116 mg/kg PVC, respectively, in the emissions from combustion of PVC with metals. Monochloronaphthalenes, dichloronaphtahlenes, monochlorophenanthrenes, and monochloroanthracenes were the predominant homologues. The other $\mathrm{CN}$ homologues were minor combustion byproducts. Detection of CNs in the PVC combustion emissions suggests that $\mathrm{CN}$ formation from solid waste incineration is a source of CNs in the environment.
\end{abstract}

(C) 2006 Published by Elsevier B.V.

Keywords: PVC; Combustion; Metals; Polychlorinated naphthalenes

\section{Introduction}

Chloronaphthalenes (CNs) are persistent and widely distributed in the environment. The trade names of $\mathrm{CN}$ industry products include Halowaxes, Nibren waxes, Seekay waxes, and Clonacire waxes. Technical $\mathrm{CN}$ formulations have many industrial applications including cable insulation, wood preservation, engine oil additives, electroplating masking compounds, feedstock for dye production, dye carriers, impregnating agents for condensers and capacitors, and refractive index testing oils [1] because of their chemical and thermal stability, good weather resistance, good electrical insulate properties, and low flammability. The production of CNs was restricted soon after their serious occupational health effects such as chloracne and liver damages were found [2].

CNs become of concern because of their toxicity, persistence, and bioaccumulation potential. It was reported that some higher chlorinated $\mathrm{CN}$ congeners can induce hepatic drug-metabolism

\footnotetext{
* Corresponding author. Tel.: +86 1062919177 ; fax: +86 1062923563.

E-mail address: xuxb1006@tom.com (X. Xu).
}

activity such as 7-ethoxyresorufin-o-deethylase and aryl hydrocarbon hydroxylase $[3,4]$. Some $\mathrm{CN}$ congeners exhibit dioxinlike toxicity [3-5]. Therefore, $\mathrm{CNs}$ are proposed to add to the list of banned or restricted chemicals by the United Nations Economic Commission for Europe Convention on Long-Range Transboundary Air Pollution-Protocol on Persistent Organic Pollutants [6]. They have been found in river sediment [7-10], aquatic biota [7,8,11-15], human adipose tissue [16], and arctic air [17].

Another important source of CNs other than $\mathrm{CN}$ industry products is municipal waste incineration and other thermal processes, which CNs were detected in fly ash $[18,19]$ and in emissions from waste incineration plants [20-22]. Studies demonstrated that thermal waste treatment of polyvinylchloride (PVC) can form polychlorinated dibenzo- $p$-dioxins and furans $(\mathrm{PCDD} / \mathrm{Fs})$, particularly in the presence of metals [23-26]. However, few studies were done on $\mathrm{CN}$ formation from PVC combustion and solid waste incineration. This study was designed to measure possible formation of $\mathrm{CNs}$ and other polychlorinated aromatics in emissions from PVC combustion with or without the presence of copper, iron, or aluminum. 


\section{Experimental}

\subsection{Materials and reagents}

PVC powder, free of additives, was product of Beijing Second Chemical Factory. Copper, aluminum, and iron powder were from Beijing Hongxing Chemical Factory, Beijing Xizhong Chemical Factory, and Britain Johnson Matthey Chemicals Ltd., respectively. All solvents were redistilled in all-glass apparatus prior to use. Halowax $1014(100 \mu \mathrm{g} / \mathrm{mL}$ in hexane), 2-chloronaphthalene (2-monoCN), 9-chlorophenanthrene (9-monoCP), and 9-chloroanthracene (9-monoCA) were purchased from Prochem, AccuStandard Inc., Acros, and Aldrich Co., respectively. 1-Bromonaphthalene (1-BrN) was obtained from Beijing Zhonglian Reagents Refinery Chemicals Ltd. 9, 10Dichloroanthracene $(9,10$-diCA) was synthesized according to the reported method [27] and the purity was $>97 \%$.

Glass wool and glass fiber filter were cleaned with methylene chloride for $6 \mathrm{~h}$ in a Soxhlet apparatus, and dried prior to use. XAD-2 adsorbent was cleaned successively with methylene chloride and methanol in a Soxhlet apparatus for $12 \mathrm{~h}$. Silica gel (100-200 mesh) was activated at $130^{\circ} \mathrm{C}$ for $16 \mathrm{~h}$. Neutral alumina (100-200 mesh) was activated at $550^{\circ} \mathrm{C}$ for $16 \mathrm{~h}$ and deactivated with $10 \%$ water. Activated carbon powder was washed with methanol, vacuum-filtered through a glass fiber filter (Gelman Sciences Inc. A/E, $1 \mu \mathrm{m}$ pore size), and dried at $130{ }^{\circ} \mathrm{C}$ for $72 \mathrm{~h}$. Activated carbon/silica (1:20, w/w) mixture was activated at $130^{\circ} \mathrm{C}$ for $24 \mathrm{~h}$, and then stored in desiccators.

\subsection{Combustion procedure}

The combustion tests were performed in a tube-type furnace, which consisted of a quartz tube of $80 \mathrm{~cm}$ length $\times 4 \mathrm{~cm}$ inner diameter and an enclosing furnace of $50 \mathrm{~cm}$ length (Fig. 1). The furnace was heated up to $900{ }^{\circ} \mathrm{C}$ followed by introduction of air into the quartz tube at a flow rate of $2 \mathrm{~mL} / \mathrm{min}$, which the temperature was controlled by the thermocouple. A quartz sample boat filled with PVC ( $1.0 \mathrm{~g})$ and metal powder $(0.03 \mathrm{~g})$ was pushed into the combustion zone. Glass fiber wool and glass fiber membrane were used to trap particulate emissions from combustion, and a XAD-2 adsorbent cartridge and cold traps with liquid nitrogen were used for sampling volatile emissions. The combustion lasted approximately $2.5 \mathrm{~min}$. Data were average of two independent experiments.

\subsection{Extraction and clean-up}

After cooling, sample boat, glass fiber wool, glass fiber membrane, and XAD-2 adsorbents were collected and extracted with methylene chloride in a Soxhlet apparatus for $18 \mathrm{~h}$. The quartz tube and cold trap of liquid nitrogen were washed with methylene chloride. The extracts and washes were combined and concentrated to $8 \mathrm{~mL}$ using a K-D apparatus, and then a gentle nitrogen stream. The extracts were spiked with $1-\mathrm{BrN}$ internal standard at $2.9 \mu \mathrm{g} / \mathrm{mL}$, and then cleaned up on a column of silica gel overlaid with deactivated neutral alumina [17]. The analytes were eluted with $n$-hexane and further fractionated with a column activated carbon/silica mixture (1:20, w/w) [15], which was eluted with a mixture of methylene chloride and $n$-hexane (3:7, $\mathrm{v} / \mathrm{v}$ ) followed by $60 \mathrm{~mL}$ of toluene. The toluene eluate was concentrated to $200 \mu \mathrm{L}$ for $\mathrm{CN}$ analysis.

\subsection{Instrumental analysis}

$\mathrm{CNs}$ and CA/CPs were analyzed with an Agilent 6890 GC/5973 MSD with electron impact ionization (EI) at $70 \mathrm{eV}$ and in selected ion monitoring (SIM) mode. GC was equipped with a HP $5 \mathrm{~ms}$ fused-silica capillary column $(30 \mathrm{~m}, 0.25 \mathrm{~mm}$ i.d., and $0.25 \mu \mathrm{m}$ film thickness). The oven was ramped from $90{ }^{\circ} \mathrm{C}$, held for $1 \mathrm{~min}$, to $180^{\circ} \mathrm{C}$ at $15^{\circ} \mathrm{C} / \mathrm{min}$, held at $180^{\circ} \mathrm{C}$ for $2 \mathrm{~min}$, and then to $280^{\circ} \mathrm{C}$ at $4{ }^{\circ} \mathrm{C} / \mathrm{min}$ and held for $20 \mathrm{~min}$. Injector, ion source, and quadrupole temperatures were 280, 230, and $250{ }^{\circ} \mathrm{C}$, respectively. An aliquot of $1 \mu \mathrm{L}$ of extract was injected in splitless mode and the purge time was $1 \mathrm{~min}$.

The analytes were identified by comparison of retention times and ratio of the selected ions with those of appropriate standards (Table 1). The standard solutions contained Halowax 1014, 2monoCN, 9-monoCP, 9-monoCA, 9, 10-diCA, and 1-BrN in isopropane. Di- to octaCNs $\left(\sum \mathrm{CN}\right)$ were quantified against a Halowax 1014 technical CN mixture of known composition

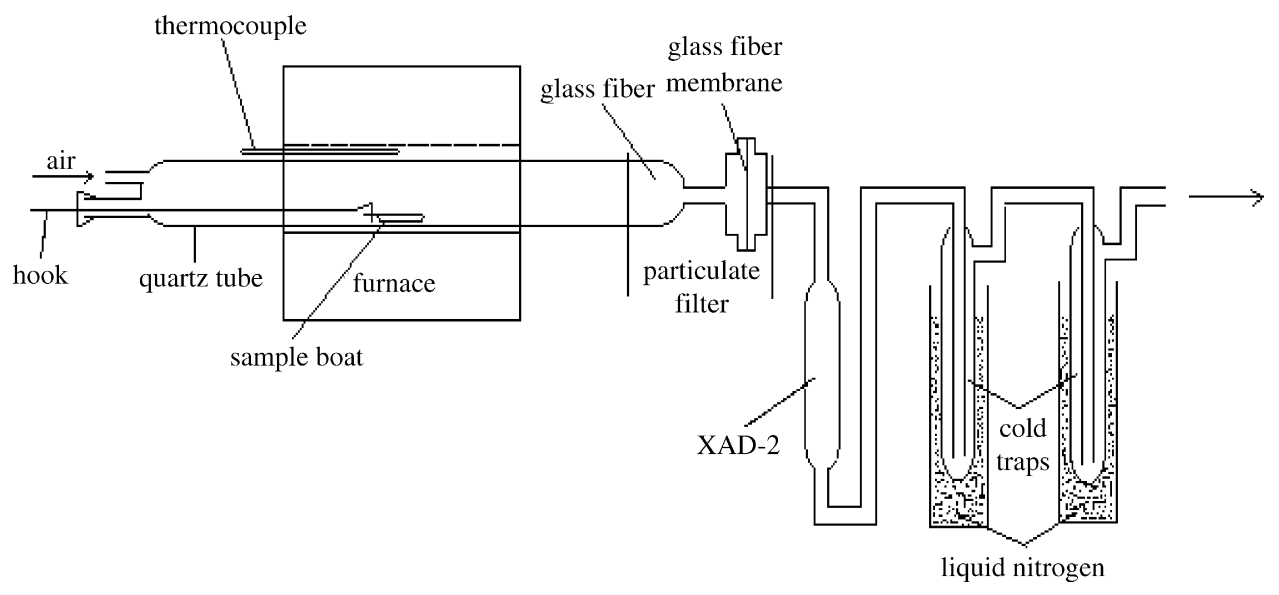

Fig. 1. A schematic diagram of the experimental apparatus for PVC combustion. 
Table 1

Ions monitored and chromatographic windows in analysis of CNs and CP/CAs with HRGC/MSD

\begin{tabular}{lllll}
\hline Compounds & $M$ & $M+2$ & $\begin{array}{l}\text { Isotopic ratio } \\
M / M+2\end{array}$ & $\begin{array}{l}\text { Time interval } \\
(\mathrm{min})\end{array}$ \\
\hline MonoCNs & 162 & 164 & 3.05 & $10.0-24.0$ \\
DiCNs, 1-BrN & 196,206 & 198,208 & 1.55 & $24.0-31.0$ \\
TriCNs & 230 & 232 & 1.04 & $31.0-35.4$ \\
TetraCNs, monoCP/CAs & 264,212 & 266,214 & $0.78,3.05$ & $35.4-40.5$ \\
PentaCNs, diCP/CAs & 300,246 & 302,248 & $1.55,1.55$ & $40.5-45.0$ \\
HexaCNs & 334 & 336 & 1.24 & $45.0-50.5$ \\
HeptaCNs & 368 & 370 & 1.04 & $50.5-54.5$ \\
OctaCN & 402 & 404 & 0.89 & $54.5-57.5$ \\
\hline
\end{tabular}

[28], and monoCNs, monoCP/CA, and diCA were quantified with 2-monoCN, 9-monoCP, and 9,10-diCA, respectively. The concentrations of congeners present in combustion products but absent in the standard solutions were estimated with their corresponding homologue standard congeners, which homologues were indicated in SIM-MS.

\subsection{Quality assurance and quality control}

A procedural blank was run to confirm that all materials, reagents, and glassware were free of $\mathrm{CNs}$ and $\mathrm{CP} / \mathrm{CAs}$. Method recoveries and reproducibility were determined with glass fiber filters spiked with the composite standard solution in triplicates. The average recoveries ranged from 46 to $117 \%$ with relative standard deviations (R.S.D.s) of $4-15 \%$ for tri- to octaCN congeners and $\mathrm{CP} / \mathrm{CAs}$. The recoveries of mono- and diCN congeners ranged from 33 to $38 \%$ due to their high volatility [2]. The recoveries of the internal standard 1-BrN in individual samples were in a range of $40-80 \%$. The limits of detection (LODs), defined as a signal-to-noise of 3:1 in blank samples, were in a range of $0.1-5.1 \mu \mathrm{g} / \mathrm{kg}$ PVC.

\section{Results and discussion}

\subsection{CNs released from PVC combustion}

The total amount of CNs emitted from PVC combustion was very similar (40-48 mg/kg PVC) under conditions with or with- out metals (Table 2). The amount of mono-, di-, and triCNs accounted for $98 \%$ of total CNs from pure PVC combustion and 94, 95, and 95.6\% from combustion of PVC with iron (Fe), copper $(\mathrm{Cu})$, and aluminum $(\mathrm{Al})$, respectively. Tetra-, penta-, hexa-, hepta-, and octaCNs accounted for $0.019-3.8 \%$ of total CNs. The $\mathrm{CN}$ homologue pattern is similar to that found in the gas phase emission from the municipal solid waste incinerators (MSWI) [2]. The results of this study indicate that combustion of PVC in MSW can form CNs. It is very important to note that combustion of $\mathrm{PVC}$ in presence of $\mathrm{Fe}, \mathrm{Cu}$, or $\mathrm{Al}$ emitted higher amounts of highly chlorinated CNs (tera-, penta-, and hexaCNs) than with no metal control (Table 2). It is known that highly chlorinated $\mathrm{CNs}$ are more toxic, persistent, and bioaccumulative in the environment than lower chlorinated ones $[9,10,15,16]$.

Fig. 2 shows specific $\mathrm{CN}$ congener profiles in the PVC combustion emissions. The dominant order of $\mathrm{CN}$ congeners was CNs 1, 2, 5, 19, 24, and 41 in the emissions from PVC combustions. In general, the levels of individual triCN to octaCN congeners decreased as the degree of chlorination increased. CNs $42,33 / 34 / 37,47,52 / 60,50,57,66 / 67,64 / 68$, and 74 were the abundant congeners in their own homologue groups. They were also found in municipal waste incinerator, cement kiln and iron sintering plant fly ashes. For example, CNs 52/60 and 66/67 were the most abundant congeners in medical and municipal waste incinerator fly ashes, and were suggested to be a good indicator for combustion processes [19,29,30]. Although CNs $35,38,57,62,53,59$, and 75 were not found in PVC combustion, they were found in the range of $0.76 \mu \mathrm{g} / \mathrm{kg}$ PVC $-0.121 \mathrm{mg} / \mathrm{kg}$ $\mathrm{PVC}$ in the emissions from combustion of PVC combined with metals (Fig. 2). CNs 35 and 62 were also identified in the fly ash samples from other incinerators [18]. These results suggest that $\mathrm{Cu}, \mathrm{Fe}$, and $\mathrm{Al}$ have catalytic effects on the formation of highly chlorinated CNs from PVC combustion and therefore the removal of metals from the incinerators prior to burning should be practiced to minimize formation of highly chlorinated CNs.

Many CNs interact with the aryl hydrocarbon receptor [3,4]. Toxic equivalent factors (TEFs) of CNs 57, 63, 64, 66/67, 68, 69 , and 73 are $3.5 \times 10^{-6}, 2 \times 10^{-3}, 2 \times 10^{-5}, 1.3 \times 10^{-3}$, $1.5 \times 10^{-4}, 2 \times 10^{-3}$, and $3 \times 10^{-3}$, respectively, as determined with H4IIE enzyme induction assays [3,4]. CNs 63, 66/67, 69, and 73 were detected in the emissions (Fig. 2) and were the most potentially toxic congeners. Total toxic equivalents ( $\left.\sum \mathrm{TEQs}\right)$ of

Table 2

Concentrations (mg/kg PVC), mass percent distribution (in parentheses) of CN homologues, and $\sum \mathrm{TEQs}(\mu \mathrm{g} / \mathrm{kg}$ PVC) of dioxin-like CN congeners released from PVC combustion

\begin{tabular}{|c|c|c|c|c|}
\hline Homologues & $\mathrm{PVC}$ & $\mathrm{PVC} / \mathrm{Fe}$ & $\mathrm{PVC} / \mathrm{Cu}$ & PVC/Al \\
\hline MonoCNs & $20.0(47)$ & $10.3(22)$ & $14.6(37)$ & $20.5(50)$ \\
\hline DiCNs & $19.1(45)$ & $28.1(59)$ & $19.1(48)$ & $14.6(36)$ \\
\hline TriCNs & $2.66(6.2)$ & $6.19(13)$ & 4.07 (10) & $3.92(9.6)$ \\
\hline TetraCNs & $0.472(1.1)$ & $1.79(3.8)$ & $1.03(2.6)$ & $0.94(2.3)$ \\
\hline PentaCNs & $0.20(0.46)$ & $1.06(2.2)$ & $0.77(1.9)$ & $0.61(1.5)$ \\
\hline HexaCNs & $0.04(0.10)$ & $0.14(0.30)$ & $0.13(0.33)$ & $0.08(0.19)$ \\
\hline HeptaCN & $<0.01(0.019)$ & $<0.01(0.038)$ & $<0.01(0.025)$ & $<0.01(0.025)$ \\
\hline OctaCN & $<0.01(\mathrm{nd})$ & $<0.01(0.0027)$ & $<0.01(0.0030)$ & $<0.01(0.0019)$ \\
\hline$\sum \mathrm{CNs}$ & 42.6 & 47.6 & 39.7 & 40.6 \\
\hline$\sum \mathrm{TEQs}^{\mathrm{a}}$ & 0.0533 & 0.246 & 0.246 & 0.291 \\
\hline
\end{tabular}

${ }^{a}$ TEFs used in TEQ calculations refer to previous studies [3-5]. 

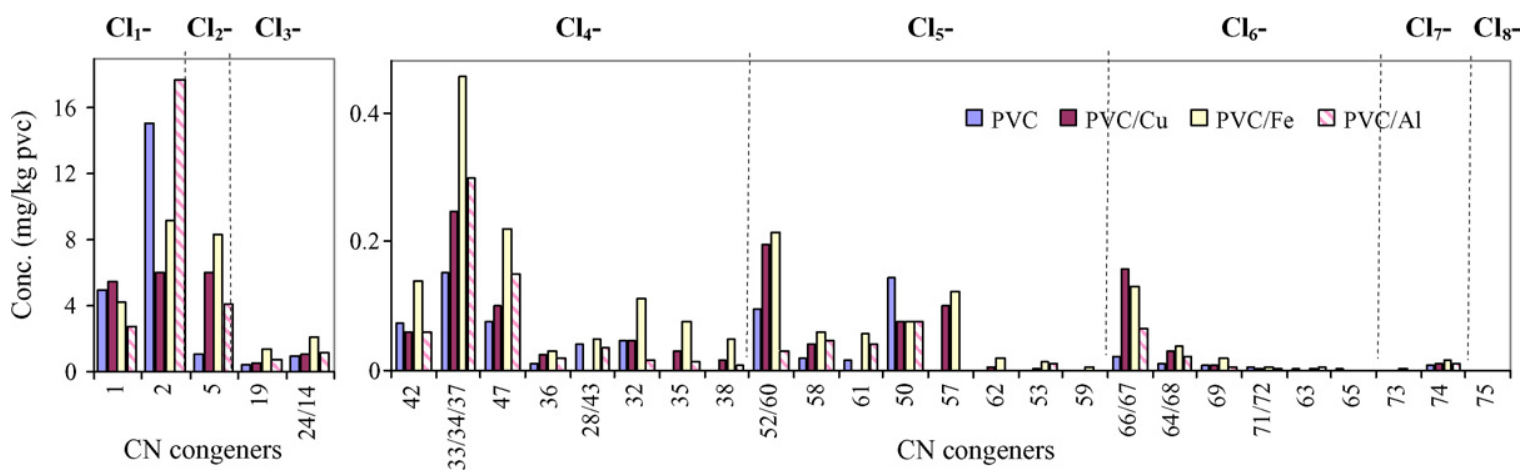

Fig. 2. Mass distribution of $\mathrm{CN}$ congeners from mono- to octaCNs released from $\mathrm{PVC}$ combustion (mg/kg PVC).

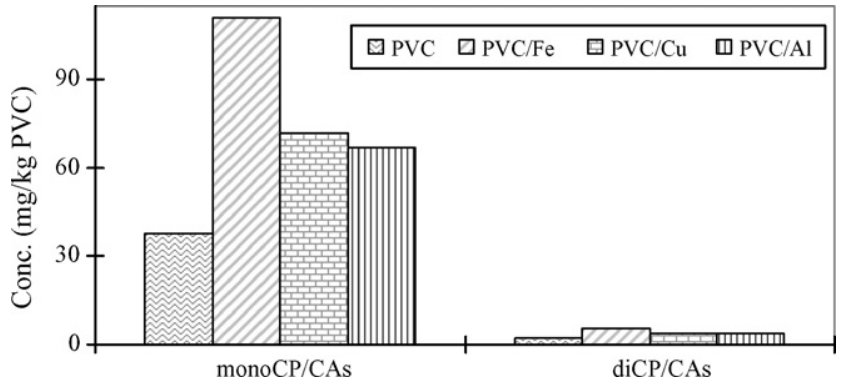

Fig. 3. CP/CAs homologue distribution in emissions from PVC combustions $(\mathrm{mg} / \mathrm{kg} \mathrm{PVC})$.

the eight CNs in the emissions from PVC combustion without metals was $0.0553 \mu \mathrm{g} / \mathrm{kg}$ PVC, but $\sum$ TEQs of these CNs in the emissions from combustion of PVC combined with metals increased to about $0.3 \mu \mathrm{g} / \mathrm{kg}$ PVC (Table 2).

\subsection{CP/CAs released from PVC combustion}

Fourteen CP/CAs in the combustion emissions from PVC with or without presence of $\mathrm{Fe}, \mathrm{Cu}$, or $\mathrm{Al}$ were well separated and detected with GC-MS. Although the CP/CAs homologues were clearly distinguished with GC-MS, their specific congeners were not identified due to lack of the standards. Fig. 3 shows the CP/CAs homologue distribution in the emissions from PVC combustions. The levels of monoCP/CAs emitted from combustion of PVC with metals were two- to three-fold of those from PVC combustion alone. There was no significant difference in the amount of diCP/CAs formed at various experimental conditions (Fig. 3).

\section{Conclusion}

The results of this study showed releases of a large quantity of CNs and CP/CAs from PVC combustion. Metals enhanced emissions of the highly chlorinated CNs in PVC combustion processes. Some CNs found in solid waste incineration were also detected in the emissions from PVC combustions. The results suggest that PVC is a major source of $\mathrm{CNs}$ and $\mathrm{CP} / \mathrm{CAs}$ formation from solid waste incineration. Separation of PVC from municipal waste streams is a possible effective means to reduce emissions of chloroaromatic compounds from incinerators.

\section{Acknowledgements}

This research was supported by grants RCEES 9906 and NSFC 29837180. The authors are grateful to the technical support of Agilent Tech. Co.

\section{References}

[1] M.J. Crookes, P.D. Howe, Environmental Hazard Assessment: Halogenated Naphthalenes, Report TSD/13, Toxic Substances Division, Directorate to Climate and Toxic Substances Environmental Department, London, UK, 1993.

[2] J. Falandysz, Polychlorinated naphthalenes: an environmental update, Environ. Pollut. 101 (1998) 77-90.

[3] A.L. Blankenship, K. Kannan, S.A. Villalobos, D.L. Villeneuve, J. Falandysz, T. Imagawa, E. Jakobsson, J.P. Giesy, Relative potencies of individual polychlorinated naphthalenes and Halowax mixtures to induce Ah receptor-mediated responses, Environ. Sci. Technol. 34 (2000) $3153-$ 3158.

[4] D.L. Villeneuve, K. Kannan, J.S. Khim, J. Falandysz, V.A. Nikiforov, A.L. Blankenship, J.P. Giesy, Relative potencies of individual polychlorinated naphthalenes to induce dioxin-like responses in fish and mammalian in vitro bioassays, Arch. Environ. Contam. Toxicol. 39 (2000) $273-$ 281.

[5] A. Hanberg, M. Stahlberg, A. Georgellis, C. de Wit, U.G. Ahlberg, Swedish dioxin survey: evaluation of the H-4II E bioassay for screening environmental samples for dioxin-like enzyme induction, Pharmacol. Toxicol. 69 (1991) 442-449.

[6] E.J. Van de Plassche, A.M.G.R. Schwegler, F. Balk, Preliminary Risk Profile-Polychlorinated Naphthalenes, Ministry of VROM/DGM, 2001.

[7] U. Järnberg, C. Asplund, C. de Wit, A.K. Grafström, P. Haglund, B. Jansson, K. Lexén, M. Strandell, M. Olsson, B. Jonsson, Polychlorinated biphenyls and polychlorinated naphthalenes in Swedish sediment and biota: levels, patterns, and time trends, Environ. Sci. Technol. 27 (1993) 1364 1374.

[8] J. Falandysz, L. Strandberg, P.A. Bergqvist, S.E. Kulp, B. Strandberg, C. Rappe, Polychlorinated naphthalenes in sediment and biota from the Gdansk Basin, Baltic Sea, Environ. Sci. Technol. 30 (1996) 3266-3274.

[9] E. Eljarrat, J. Caixach, B. Jimenez, J. Rivera, Polychlorinated naphthalenes in sediments from the Venice and Orbetello Lagoons, Italy, Chemosphere 38 (1999) 1901-1912.

[10] B. Gevano, T. Harner, K.C. Jones, Sedimentary record of polychlorinated naphthalene concentrations and deposition fluxes in a dated lake core, Environ. Sci. Technol. 34 (2000) 33-38.

[11] P.A. Helm, T.F. Bidleman, G.A. Stern, K. Koczanski, Polychlorinated naphthalenes and coplanar polychlorinated biphenyls in beluga whale (Delphinapterus leucas) and ringed seal (Phoca hispida) from the eastern Canadian Arctic, Environ. Pollut. 119 (2002) 69-78.

[12] J. Falandysz, C. Rappe, Spatial distribution in plankton and bioaccumulation features of polychlorinated naphthalenes in a pelagic food chain 
in southern part of the Baltic Proper, Environ. Sci. Technol. 30 (1996) 3362-3370.

[13] K. Kannan, N. Yamashita, T. Imagawa, W. Decoen, J.S. Khim, R.M. Day, C.L. Summer, J.P. Giesy, Polychlorinated naphthalenes and polychlorinated biphenyls in fishes from Michigan waters including the Great Lakes, Environ. Sci. Technol. 34 (2000) 566-572.

[14] J. Falandysz, L. Strandberg, B. Strandberg, C. Rappe, Polychlorinated naphthalenes in three-spined stickleback Gasterosteus aculeatus from the Gulf of Gdansk, Chemosphere 37 (1998) 2473-2487.

[15] K. Kannan, K. Hilscherova, T. Imagawa, N. Yamashita, L.L. Williams, J.P. Giesy, Polychlorinated naphthalenes, -biphenyls, -dibenzo- $p$-dioxins, and -dibenzofurans in Double-Crested Cormorants and Herring Gulls from Michigan waters of the Great Lakes, Environ. Sci. Technol. 35 (2001) 441-447.

[16] D.T. Williams, B. Kennedy, G.L. Lebel, Chlorinated naphthalenes in human adipose tissue from Ontario municipalities, Chemosphere 27 (1993) 795-806.

[17] T. Harner, H. Kylin, T.F. Bidleman, C. Halsall, W.M.J. Strachan, L.A. Barrie, P. Fellin, Polychlorinated naphthalenes and coplanar polychlorinated biphenyls in arctic air, Environ. Sci. Technol. 32 (1998) 3257-3265.

[18] T. Imagawa, N. Yamashita, A. Miyazaki, Isomer-specific analysis of tetraand pentachloronaphthalene in fly ash and Halowax, J. Environ. Chem. 3 (1993) 221-230.

[19] M. Schneider, L. Stieglitz, R. Will, G. Zwick, Polychlorinated naphthalenes on fly ash, Chemosphere 37 (1998) 2055-2070.

[20] E. Abad, J. Caixach, J. Rivera, Dioxin-like compounds from municipal waste incinerator emissions: assessment of the presence of polychlorinated naphthalenes, Chemosphere 38 (1997) 109-120.

[21] A. Yasuhara, M. Morita, Formation of chlorinated aromatic hydrocarbons by thermal decomposition of vinylidene chloride polymer, Environ. Sci. Technol. 22 (1988) 646-650.
[22] E. Benfenati, G. Mariani, R. Faneli, S. Zuccotti, "De novo" synthesis of PCDD, PCDF, PCN, PCB and PAH in a pilot incinerator, Chemosphere 22 (1991) 1045-1052.

[23] T. Katami, A. Yasuhara, T. Okuda, T. Shibamoto, Formation of PCDDs, PCDFs, and coplanar PCBs from polyvinyl chloride during combustion in an incinerator, Environ. Sci. Technol. 36 (2002) 13201324.

[24] D. Wang, X. Xu, M. Zheng, C.H. Chiu, Effect of copper chloride on the emissions of PCDD/Fs and PAHs from PVC combustion, Chemosphere 48 (2002) $857-863$

[25] D. Wang, X. Xu, S. Chu, D. Zhang, Analysis and structure prediction of chlorinated polycyclic aromatic hydrocarbons released from combustion of polyvinylchloride, Chemosphere 53 (2003) 495-503.

[26] W.F. Carroll Jr., T.C. Berger, F.E. Borrelli, P.J. Garrity, R.A. Jacobs, J. Ledvina, J.W. Lewis, R.L. McCreedy, T.P. Smith, D.R. Tuhovak, A.F. Weston, Characterization of emissions of dioxins and furans from ethylene dichloride, vinyl chloride monomer and polyvinyl chloride facilities in the United States, Chemosphere 43 (2001) 689-700.

[27] I. Tanimoto, E. Kushioka, T. Kitagawa, K. Maruyama, Binary phase chlorination of aromatic hydrocarbons with solid copper (II) chloride: reaction mechanism, Bull. Chem. Soc. Jpn. 52 (1979) 35863591.

[28] T. Harner, T.F. Bidleman, Polychlorinated naphthalenes in urban air, Atmos. Environ. 31 (1997) 4009-4016.

[29] P.A. Helm, T.F. Bidleman, Current combustion-related sources contribute to polychlorinated naphthalenes and dioxin-like polychlorinated biphenyl levels and profiles in air in Toronto, Canada, Environ. Sci. Technol. 37 (2003) 1075-1082.

[30] T. Imagawa, C.W. Lee, Correlation of polychlorinated naphthalenes with polychlorinated dibenzofurans formed from waste incineration, Chemosphere 44 (2001) 1511-1520. 